\title{
The instrumental cultivation of Phlojodicarpus sibiricus cell culture
}

Khandy M.T. ${ }^{1,2 *}$, Sofronova A.K. ${ }^{3}$, Tomilova S.V. ${ }^{4}$, Klyushin A.G. ${ }^{4}$, Nosov A.M. ${ }^{4}$

${ }^{1}$ FSC East Asia Terrestrial Biodiversity, FER RAS, Vladivostok, Russia

${ }^{2}$ M.K. Ammosov North-Eastern Federal University, Yakutsk, Russia

${ }^{3}$ Far Eastern Federal University, Vladivostok, Russia

${ }^{4}$ K.A. Timiryazev Institute of Plant Physiology RAS, Moscow, Russia

* email: handy_89@mail.ru

In this study, the cultivation of Phlojodicarpus sibiricus cells was carried out in two types of bioreactors. The object of the study was $P$. sibiricus suspension culture. Cells were grown in MS medium with phytohormones. For the cultivation were used bioreactors with different types of stirring devices: 1) A stirring tank bioreactor, with a total volume of 7.51.2) A bubble column bioreactor, with a total volume of 211 . The air supply rate for aeration is from 0.17 to 0.251 per 11 of the culture medium per minute. The optimum planting density of the inoculum in the bioreactor for dry biomass was $1 \mathrm{~g} / \mathrm{l}$ (determined experimentally). During cultivation, the viability and growth characteristics of cell cultures were determined by dry biomass: growth index (I), specific growth rate $(\mu)$. From the results obtained, it follows that instrumental cell growth in a bubble column bioreactor leads to stable growth of the culture with a lag phase duration of about 3 days and an improvement in its main growth parameters relative to flasks $\left(\mathrm{I}=12.7 ; \mu=0.18\right.$ day $\left.^{-1}\right)$. On the contrary, when using a stirring tank bioreactor, a deterioration in growth parameters was noted $\left(I=7.6 ; \mu=0.13\right.$ day $\left.^{-1}\right)$. Growth rates decrease was obtained in the earlier works with cell cultures of other species (Dioscorea deltoidea, Panax japonicus, Stephania glabra). An improvement in growth characteristics in a bubble column bioreactor is presumably associated with an increase of cell aeration, and a deterioration in growth when using a stirring tank bioreactor - with a damaging effect on cells of stirring devices. Thus, the instrumental cultivation of the $P$. sibiricus suspension was carried out for the first time.

Acknowledgements: The results were obtained as part of the state task of the Ministry of Education and Science of Russia (FSRG-2020-0019). 